consumer goods and services, has no screening procedures, and lacks any legal sanction.

The BMA is accused by the commission of causing confusion because its ethical guidance is more restrictive than that issued by the General Medical Council. As is clearly stated in the BMA guidance, however, it is intended to provide doctors with advice on advertising that they can follow with complete safety: the guidance makes it clear that it is not mandatory. The commission admits receiving no evidence of confusion. (Perhaps it is the commission and not the profession that is confused.) The BMA will now have to bring its guidance into exact conformity with that of the General Medical Council (which will destroy its value to practising doctors) or risk heavy penalties under the restrictive practices legislation.

Secretary,

J D J HAVARD

BMA

1 Monopolies and Mergers Commission. Services of medical practitioners. London: Monopolies and Mergers Commission, 1989. (Cmnd 583.)

2 Robinson JC, Luft HS. Competition and the cost of hospital care 1972-1982. FAMA 1987;257: $3241-5$

\title{
Obstructive sleep apnoea and driving
}

\section{Sufferers need medical advice}

Doctors in Britain have been slow to recognise obstructive sleep apnoea, but now their awareness has increased and more respiratory physicians are investigating and treating this disorder. In obstructive sleep apnoea recurrent collapse and closure of the pharyngeal airway during sleep leads to loud snoring and repeated episodes of hypoxia and arousal of which the patient is unaware. As there may be more than 300 such arousals every night the dominant symptom is daytime sleepiness with poor concentration and frequent "microsleeps," particularly during boring activities. ${ }^{1}$

Although such sleepiness may be personally disastrous (for example, resulting in loss of a job, marital strife, and a reduced quality of life), it may also hazard both patients and others if they fall asleep while driving. These patients often report loss of concentration while driving, particularly on motorways in the dark, when incoming sensory information and activity is low, though more exciting activities will still maintain arousal. Truthful answers about sleepiness during driving may be difficult to obtain owing to patients' fears about losing their driving licence. Thus, as regards fitness to drive, obstructive sleep apnoea should be classified with epilepsy, hypoglycaemia, and Adams-Stokes attacks.

Many long distance lorry drivers have obstructive sleep apnoea $^{23}$ as they commonly have the major risk factor, obesity. In their survey of truck accidents in which the driver is killed, the American National Transportation Safety Board is now asking relatives routinely about features of obstructive sleep apnoea, given that three recent reports have shown that the road traffic accident rate of patients with this condition is up to seven times greater than that of normal drivers. ${ }^{47}$ The proportion of crashes in which the driver was at fault and the number of traffic violations were both appreciably higher in patients with obstructive sleep apnoea than in other drivers; moreover, about one third of the patients had had car crashes in the previous five years. ${ }^{58}$

The prevalence of sleep apnoea and excessive daytime sleepiness is not known, but estimates vary between $0.01 \%$ and $5 \%$ of men, depending on the exact definition used..$^{10}$ Obstructive sleep apnoea resembles hypertension in that there is a continuum from normality to severe abnormality, and the importance of the less severe forms is not clear. In a survey of over 500 men drawn randomly from a general practice about $5 \%$ had some evidence of obstructive sleep apnoea on overnight oximetry (J Crosby et al, paper to the British Thoracic Society, December 1988). "Do you have to pull off the road while driving due to sleepiness" was the only question about sleepiness admitted to more often by this $5 \%$ compared to the rest, a small but significant difference (unpublished data).

Excessive sleepiness can be investigated either with tests of sleep latency ${ }^{11}$ (the time taken to fall asleep, measured during several deliberate attempts to do so) or, perhaps more appropriately, with long and boring vigilance tests. ${ }^{12}$ The difficulty of simulating the low sensory input of long motorway journeys explains the paucity of laboratory work on this problem. Nevertheless, in most subjects ${ }^{1314}$ the mean of 120 measurements of the reaction time following the random presentation of a visual stimulus, over 10-15 minutes, is a sensitive index of one night's sleep deprivation, and almost as good as the one hour Wilkinson vigilance test. ${ }^{14}$ Lapses of concentration produce excessively long reaction times; in our laboratory normal subjects have a response time of 308 (SD 33) ms whereas over half our patients with obstructive sleep apnoea and other causes of sleepiness (such as the narcolepsy syndrome) have reaction times more than 2 standard deviations ( $374 \mathrm{~ms}$ ) above the mean (unpublished data).

How should a doctor advise a patient who drives, has obstructive sleep apnoea, and complains of sleepiness? If there is a history of recurrent sleepiness while driving the patient should certainly be advised to stop driving and also to inform the Driving and Vehicle Licensing Centre in Swansea if treatment is not expected to cure the condition within three months. Patients have a responsibility to do this and doctors are responsible for advising them. With lesser degrees of sleepiness, such as anyone might have after a few nights of broken sleep, the answer is not clear. Nevertheless, patients should be told that this condition can impair driving and that it is common sense not to drive if feeling at all sleepy. An insurance company might well resist a claim if a client was found to have been driving against medical advice. In cases of doubt the medical department at the Driving and Vehicle Licensing Centre should be consulted. All patients with obstructive sleep apnoea who hold public service vehicle licences or heavy goods vehicle licences should be advised to stop driving until effective treatment has been arranged. At present there is no justification for being more stringent than this, given that we do not know the relative risk of a patient with obstructive sleep apnoea having a car accident, compared with patients with other medical disorders that are currently regarded as compatible with continued driving.

Effective treatment for obstructive sleep apnoea is available and dramatically reduces the symptoms due to fragmentation of sleep. The treatment depends on the severity of the condition, ranging from simple advice to lose weight and stop 
drinking alcohol after $6 \mathrm{pm}$, through to providing nasal continuous positive airway pressure ${ }^{15}$ or, in selected cases, pharyngeal surgery. ${ }^{16}$

Finally, given that the prevalence of symptomatic sleep apnoea is not known, we need more epidemiological research to clarify its contribution to deaths on our roads - with tests of vigilance and performance together with confidential inquiries into the causes of accidents, which should include questions to detect sleepiness and obstructive sleep apnoea.

Wellcome Senior Research Fellow and

J R STRADLING

Honorary Consultant,

Osler Chest Unit, Churchill Hospital,

Oxford OX3 7LJ

1 Stradling JR, Phillipson EA. Breathing disorders during sleep. Of Med 1986;58:3-18.

2 Gillespie K. Sleep apnea on our highways. Association of Professional Sleep Societies Newsletter 1988;3(1):19.

3 Bolz EA. Sleep apnea on our highways. Association of Professional Sleep Societies Newsletter Bolz EA. Sleep
+ Lauber JK, Kayten PJ. Sleepiness, circadian dysrhythmia, and fatigue it transportation system accidents. Sleep 1988;11:503-12.

Findley $\mathrm{L}$, Unverstadt $M$, Suratt $P$. Automobile accidents in patients with obstructire sleep apnea. Am Rev Respir Dis 1988;138:337-40.

6 George C, Nickerson P, Hanly P, Millar T, Kryger M. Sleep apnoea patients have more automobile accidents. Lancet 1987;ii:447.

Gonzalez-Rothi RJ, Foresman GE, Block AJ. Do patients with sleep apnea die in their sleep? Chest 1988:94:531-8.

8 Findley LJ, Bonnie RJ. Sleep apnea and auto crashes. Chest 1988;94:225-6.

9 Lavie P. Sleep habits and sleep disturbance in industrial workers in Israel: main findings and some charatteristics of workers complaining of excessive daytime sleepiness. Sleep 1981:4:147-58.

10 Lavie $P$. Incidence of sleep apnea in a presumably healthy working population: a significan relationship with excessive daytime sleepiness. Sleep 1983;6: 312-8.

11 Richardson G, Carskadon M, Flagg W, van den Hoed J, Dement W, Mitler M. Excessive daytime sleepiness in man: multiple sleep latency measurements in narcoleptic and control subjects. Electroencephalogr Clin Neurophysiol 1987; 45:621-7.

12 Wilkinson RT. Sleep deprivation: performance tests for partial and selective sleep deprivation. In Abt L, Riess B, eds. Progress in clinical psychology. Vol 8. New York: Grune and Stratton, 1968:28-43.

13 Wilkinson RT, Houghton D. Field test of arousal: a portable reaction timer with data storage. Hum Factors 1982;24:487-93.

14 Glenville $M$, Broughton $R$, Wing AM, Wilkinson RT. Effects of sleep deprivation on short duration performance measures compared to the Wilkinson auditory vigilance task. Sleep 1978;1:169-76.

15 Sullivan CE, Issa FG, Berthon-Jones M, McCauley VB, Costas LJV. Home treatment of obstructive sleep apnoea with continuous positive airway pressure applied through a nose-mask. Bull Eur Physiopathol Respir 1984;20:49-54.

16 Conway W, Fujita S, Zorick F, et al. Uvulopalatopharyngoplasty: a one year follow up. Chest $1985 ; 88: 385-7$.

\section{Educating children and young people with special needs}

\section{Many children missing out}

Words change, but problems may remain: handicapped children are now children with "special needs"; "learning difficulties" is replacing mental handicap. Changes in names have been accompanied by new approaches, but a recent survey suggests that the needs of children with special problems are often not met. The report, by the National Association of Health Authorities (NAHA), summarised the problem as "one of resources, both financial and human. NAHA and the Council for Local Education Authorities believe that the time has now come for government to take seriously its responsibilities in the implementation of the 1981 Education Act and to provide additional resources which can enable a proper response to be made to expressed needs."

The 1981 Education $\mathrm{Act}^{2}$ together with the clarifying circular ${ }^{3}$ formalised many of the recommendations of the 1978 Warnock report, which was the first thorough review of the arrangements for educating handicapped children and young people in Britain. ${ }^{+}$Before the act children with impairments or disabilities were labelled according to specific categories of handicap (such as "physical handicap," "delicate," “deaf," or "educationally subnormal"). One of the act's main changes was to replace this statutory labelling by the identification of special educational needs (including those needs attributable to a physical, sensory, or mental disability or an emotional or behavioural disorder).

Since 1981 local education authorities have been responsible for identifying and providing these needs. Parents are closely concerned in the process, and the importance of early recognition of possible special educational needs, often by health workers dealing with preschool children, has been accepted. Up to one in five children may have special needs during their education. Not all need multiprofessional assessment, but those with severe or complex problems (perhaps $2 \%$ of all children) require the preparation of a statement of need taking account of written educational, psychological, and medical advice and the parents' wishes. "Statemented" children require a yearly educational review and further multidisciplinary assessments if indicated and an assessment between the ages of 13 and 14 to determine their future needs. The Warnock report recommended that children with special needs should be educated in ordinary schools whenever possible, provided that this was not detrimental to the child or, by diverting educational resources, to other children.

Children with severe or complex problems in mainstream schools place an extra burden on the health servicesfor example, caring for such children and supporting the teaching staff means extra work for school nurses. More visiting physiotherapists, occupational therapists and speech therapists, and coordinating administrative staff are also needed. NAHA reports that these resources are often lacking.

Services for speech therapy have been especially under stress since the operation of the act. Most children with special needs have problems with speech and language, which require detailed assessment and treatment. The NAHA report says that many children attending mainstream schools who need speech therapy are now not receiving it, and even those in "special" educational settings are receiving a restricted service. Already limited provision has been stretched too far. The overall picture for therapy services is of greater demand on increasingly pressurised, low growth, shortage specialties. Bureaucratic delays often leave children unplaced for far too long, staff have to divert time from clinical work to preparing statements, and there is a need to spend extra time counselling parents and supporting other staff.

Accepting that most health authorities have not been able to allocate the increased resources to deal with the workload generated by the act, the report recommends disseminating good practice guides and establishing multidisciplinary training to break down professional barriers. This, the report maintains, would encourage caring, nursing, and teaching activities to focus on the child's needs. There were no doubts raised about the act's good intentions or positive effects, but repeated concern was expressed about its inadequate implementation.

The shortfall between need and available resources has resulted in "compromised statementing" to avoid a gap between parents' expectations and available local services. Although the act requires that parents be informed of their 